Next morning at 5:20 a.m. the Robin starts again. I get up and shut the bedroom door so I can't hear the noise, then go back to sleep. But I am determined to outwit the Robin. So I get up to get my pruning saw and cut off the branch she sits on, and a few extra branches; so that she won't be able to look across and see her reflection in the window.

With no branches to sit on, the Robin now sits on the top of the downspout at an angle from which she cannot possibly see herself. Still she attacks the window! The only explanation I can give is that this Robin is an Alice trying to get through the looking glass.

Keith Barr, 40 Richardson Crescent, Regina, SK. S4S 4J3

\section{WHOOPING CRANES INVADE SASKATCHEWAN}

During the 1996 fall migration Whooping Cranes were observed in unprecedented numbers in Saskatchewan. At least 98 (including 10 young) of the estimated $165 \pm$ Whooping Cranes in the Wood Buffalo-Aransas flock of Whooping Cranes were reported to the Canadian Wildlife Service Whooping Crane Hot Line between late August and the end of October. The cranes were observed from Meadow Lake to Estevan, with the majority of birds being within $100 \mathrm{~km}$ of Saskatoon. The Canadian Wildlife Service monitors this population and during the summer of 1996, 44 pairs of cranes nested. In late May and in June at least 32 chicks hatched, however, as is the norm, chicks disappeared as the summer progressed and only 14 were observed in mid August. As the birds arrive on their wintering grounds at the Aransas National Wildlife Refuge in Texas they will be counted by the U.S. Fish and Wildlife Service. A total count of this population will be available by year end.

The new International Whooping Crane Recovery Team (an amalgamation of the Canadian and U.S. Recovery Teams) met for the first time this year. The team directs recovery activities for the cranes following guidelines laid out in the Whooping Crane Recovery Plan. A few of the activities that the team is involved in include: research into the habitat and food requirements of the cranes on their breeding and winter ranges; investigations into reintroduction techniques and suitable reintroduction areas; captive breeding for research and release; and introduction of birds into the wild.

For the past two years Canadian Wildlife Service staff, in cooperation with Parks Canada, have been investigating crane foods in the breeding area. Techniques used involve the identification and matching of carbon and nitrogen isotope levels in crane feathers and potential food items as well as analysis of crane droppings. Parks Canada staff have been using satellite imagery to map crane habitat and recently began classifying the habitat in the nesting area. U.S. personnel have and continue to investigate winter foods and habitat.

A new non-migratory flock (to replace the one that died out in Louisiana) is currently being established. Cranes, bred in captivity for release, are being introduced into the wild in Florida. To date about 50 birds survive with the oldest just arriving at breeding age. The Calgary Zoo, which produced their first Whooping Crane chicks this year will be sending three cranes to join others from U.S. breeding centres for release later this winter. 
Innovative research is being conducted into reintroduction techniques for establishing another migratory flock of Whooping Cranes. Sandhill Cranes are being taught to migrate with an ultra-light aircraft to establish new migration routes. Early results are encouraging but more work needs to be done before the recovery team endorses the technique as a viable option for establishing new breeding and wintering areas for Whooping Cranes. Areas under consideration for such a migratory flock include Manitoba and the southeast United States.

In the mean time the AransasWood Buffalo flock continues its slow but steady increase. The population which once numbered only 15 birds reached a high of 146 birds in 1989 but was only able to break the 150 mark this past year. The stability of the winter range in Texas continues to cause concern for the recovery team. The sooner we are able to encourage Whooping Cranes to winter in more than one locale, through establishing additional populations, the safer the survival of the Whooping Crane becomes.

Brian Johns, Canadian Wildlife Service, Saskatoon, SK.

\section{GREAT BLUE HERON EATING A RICHARDSON'S GROUND SQUIRREL}

While checking on his cattle on pasture, our neighbour, Ernie Quintal, noticed a Great Blue Heron in a stalking pose over a gopher (Richardson's Ground Squirrel), stunning it, and then grasping it in its beak. It then flew to a nearby cattle watering hole (actually a rather shallow pothole) where it upended the gopher to grasp it by its head. It then dunked the gopher in the muddy bottom of the pothole. This operation was repeated four or five times until the gopher was drowned and covered with gooey mud. The heron then raised and opened its beak and proceeded to swallow this adult gopher with apparent ease.

The above procedure was later witnessed by myself, accompanied by Ernie and several other people, at various times during a two-week period. As far as we could ascertain, it was always the same heron as it would drive other herons away if they entered on its turf. Ernie observed several gophers being consumed in a single morning. Later in the season, as water levels rose, the heron would take its kill to other more convenient water holes.

The pasture area was literally a "holey land" occupied by many of their immature offspring. Later in the summer, the young gophers were seen to be eaten directly without the drowning and mudding process; presumably because they were easier to swallow.

Water levels in this area have been very high this year, resulting in receding shorelines and possibly a shortage of suitable feeding sites for herons. Several other observations of gopher-eating herons have been reported.

The particular sighting captured on the enclosed slides took place at Ernie Quintal's farm, near Lac La Biche, Alberta: NE 1/4 Section 1-6713-W.4 on 25 June 1996.

Jerry Sykes, Lac la Biche, AB. 